\title{
Effect of bile acid sequestrants on glucose metabolism, hepatic de novo lipogenesis, and cholesterol and bile acid kinetics in type 2 diabetes: a randomised controlled study
}

\author{
C. Beysen • E. J. Murphy $\cdot$ K. Deines $\cdot$ M. Chan • \\ E. Tsang $\cdot$ A. Glass $\cdot$ S. M. Turner $\cdot$ J. Protasio • \\ T. Riiff • M. K. Hellerstein
}

Received: 7 June 2011 / Accepted: 26 September 2011 /Published online: 2 December 2011

(C) Springer-Verlag 2011

\begin{abstract}
Aims/hypothesis The primary aim of this completed multicentre randomised, parallel, double-blind placebo-controlled study was to elucidate the mechanisms of glucose-lowering with colesevelam and secondarily to investigate its effects on lipid metabolism (hepatic de novo lipogenesis, cholesterol and bile acid synthesis).

Methods Participants with type 2 diabetes $\left(\mathrm{HbA}_{1 \mathrm{c}} 6.7-\right.$ $10.0 \%$ [50-86 mmol/mol], fasting glucose $<16.7 \mathrm{mmol} / 1$, fasting triacylglycerols $<3.9 \mathrm{mmol} / \mathrm{l}$ and LDL-cholesterol $>1.55 \mathrm{mmol} / \mathrm{l}$ ) treated with diet and exercise, sulfonylurea, metformin or a combination thereof, were randomised by a central coordinator to either $3.75 \mathrm{~g} /$ day colesevelam $(n=30)$ or placebo $(n=30)$ for 12 weeks at three clinical sites in the USA. The primary measure was the change from baseline in glucose kinetics with colesevelam compared to placebo treatment. Fasting and postprandial glucose, lipid and bile acid pathways were measured at baseline and post-treatment using stable isotope techniques. Plasma glucose, insulin, total glucagon-like peptide-1 (GLP-1),
\end{abstract}

C. Beysen $(\bowtie) \cdot K$. Deines $\cdot$ M. Chan $\cdot$ E. Tsang $\cdot$ A. Glass $\cdot$

S. M. Turner $\cdot$ J. Protasio $\cdot$ T. Riiff $\cdot$ M. K. Hellerstein

Kinemed, Inc., 5980 Horton Street Suite 470,

Emeryville, CA 94608, USA

e-mail: cbeysen@kinemed.com

\section{K. Hellerstein}

Department of Nutritional Sciences, University of California,

Berkeley, CA, USA

E. J. Murphy $\cdot$ M. K. Hellerstein

Division of Endocrinology and Metabolism,

University of California,

San Francisco, CA, USA total glucose-dependent insulinotropic polypeptide (GIP), glucagon and fibroblast growth factor-19 (FGF-19) concentrations were measured during the fasting state and following a meal tolerance test. Data was collected by people blinded to treatment.

Results Compared with placebo, colesevelam improved $\mathrm{HbA}_{1 \mathrm{c}}$ (mean change from baseline of 0.3 [SD 1.1]\% for placebo $[n=28]$ and $-0.3[1.1] \%$ for colesevelam $[n=26]$ ), glucose concentrations, fasting plasma glucose clearance and glycolytic disposal of oral glucose. Colesevelam did not affect gluconeogenesis or appearance rate (absorption) of oral glucose. Fasting endogenous glucose production and glycogenolysis significantly increased with placebo but were unchanged with colesevelam (treatment effect did not reach statistical significance). Compared with placebo, colesevelam increased total GLP-1 and GIP concentrations and improved HOMA-beta cell function while insulin, glucagon and HOMA-insulin resistance were unchanged. Colesevelam increased cholesterol and bile acid synthesis and decreased FGF-19 concentrations. However, no effect was seen on fractional hepatic de novo lipogenesis.

Conclusions/interpretation Colesevelam, a non-absorbed bile acid sequestrant, increased circulating incretins and improved tissue glucose metabolism in both the fasting and postprandial states in a manner different from other approved oral agents.

Trial registration: ClinicalTrials.gov NCT00596427 Funding: The study was funded by Daiichi Sankyo.

Keywords Bile acid sequestrant · Bile acid synthesis . Cholesterol synthesis · De novo lipogenesis - Endogenous glucose production - GLP-1 - Gluconeogenesis . Glycogenolysis · Stable isotopes - Type 2 diabetes 


$\begin{array}{ll}\text { Abbreviations } \\ \text { BAS } & \text { Bile acid sequestrants } \\ \text { CA } & \text { Cholic acid } \\ \text { CDCA } & \text { Chenodeoxycholic acid } \\ \text { DNCS } & \text { De novo cholesterol synthesis } \\ \text { DNL } & \text { De novo lipogenesis } \\ \text { EGP } & \text { Endogenous glucose production } \\ \text { FGF-19 } & \text { Fibroblast growth factor-19 } \\ \text { FFM } & \text { Fat-free mass } \\ \text { FXR } & \text { Farnesoid X receptor } \\ \text { GIP } & \text { Glucose-dependent insulinotropic polypeptide } \\ \text { GLP-1 } & \text { Glucagon-like peptide 1 } \\ \text { GNG } & \text { Gluconeogenesis } \\ \text { HOMA-B } & \text { HOMA-beta cell function } \\ \text { HOMA-IR } & \text { HOMA-insulin resistance } \\ \text { MIDA } & \text { Mass isotopomer distribution analysis } \\ R_{\mathrm{a}} & \text { Rate of appearance } \\ R_{\mathrm{d}} & \text { Disposal rate } \\ \text { TGR5 } & \text { G-protein-coupled bile acid receptor }\end{array}$

\section{Introduction}

Bile acid sequestrants (BAS) such as colesevelam, colestyramine, colestipol and colestimide are effective therapies for lowering LDL-cholesterol, and work by interrupting the enterohepatic circulation of bile acids [1]. These agents form non-absorbable complexes with bile acids, which inhibits their reabsorption in the ileum [2] and increases faecal excretion. In response, the nuclear receptor farnesoid $\mathrm{X}$ receptor (FXR)-mediated inhibition of cholesterol $7 \alpha-$ hydroxylase is reduced in the liver and bile acid synthesis from cholesterol is upregulated [3] and the expression of LDL receptors is upregulated and the clearance of LDLcholesterol from the blood is increased. BAS have also been shown to improve glycaemic control in individuals with type 2 diabetes mellitus [4].

The glucose-lowering mechanism(s) of BAS are not well understood. It has been hypothesised that bile acids, via activation of FXR and the G-protein-coupled bile acid receptor (TGR5), have roles in glucose and energy homeostasis [5] and that disruption of the normal bile acid flux may lead to improved glycaemic control. BAS might modulate FXRdependent signalling pathways that regulate hepatic gluconeogenesis [6] and peripheral insulin sensitivity [7, 8]. Alternatively, BAS might promote secretion of glucagonlike peptide 1 (GLP-1) [9] and increase energy expenditure [10] via TGR5 activation. There are no data supporting these hypotheses in humans and despite a consistent glucose lowering effect, existing data suggest no change in insulin sensitivity [11] with BAS, no association between glycaemic control and bile acid metabolism [12] and no association between bile acids and energy expenditure in humans [13].
Accordingly, the primary objective of this study was to elucidate the mechanisms of glucose lowering by colesevelam through in-depth examination of glucose metabolic pathways in people with type 2 diabetes. We used stable (non-radioactive) isotopic tracers to measure the effects of colesevelam on endogenous glucose production (EGP), gluconeogenesis (GNG), glycogenolysis, fasting plasma glucose clearance, appearance of oral glucose (glucose absorption), total glucose disposal and glycolytic disposal of oral glucose. The secondary objectives were to measure the effects of colesevelam on hepatic de novo lipogenesis (DNL), de novo cholesterol synthesis (DNCS), de novo bile acid synthesis, GLP-1 and glucose-dependent insulinotropic polypeptide (GIP) concentrations.

\section{Methods}

Participants Sixty individuals (Fig. 1) with type 2 diabetes treated with diet and exercise, metformin, a sulfonylurea, or a combination of these treatments were enrolled. Exclusion criteria included fasting plasma glucose $>16.7 \mathrm{mmol} / \mathrm{l}$, fasting serum triacylglycerols $\geq 3.9 \mathrm{mmol} / 1$, LDLcholesterol $<1.55 \mathrm{mmol} / \mathrm{l}$, pregnancy or a history of liver, biliary or intestinal diseases. Participants treated with insulin or a lipid-lowering agent other than a statin at any time or treated with a thiazolidinedione less than 6 months prior to screening were excluded. All pre-existing treatments were stable for a minimum of 3 months prior to enrolment. Participants were studied at three sites: the Diabetes and Glandular Disease Research Center (DGD, San Antonio, TX, USA), Clinical Pharmacology of Miami (Miami, FL, USA) and Diablo Clinical Research (Walnut Creek, CA, USA). All participants gave written informed consent. The study was approved for all sites by the Biomedical Research Institute of America Institutional Review Board (San Diego, CA, USA).

Drug administration and randomisation This was a randomised double-blind placebo-controlled clinical trial. Participants were studied at baseline and then randomised to colesevelam or placebo for 12 weeks. Block randomisation was used to achieve a balance of sexes between groups. A central randomisation list was created by a statistician and kept by a central coordinator who provided the group allocation for each participant to an investigator at each site. All investigators involved in the randomisation process were not otherwise involved with the study. Participants received six tablets a day of either colesevelam (3.75 g/day) or matched placebo for 12 weeks: three tablets with lunch and three tablets with dinner. Study drug compliance was assessed at baseline and every 4 weeks thereafter by pill counts. During the post-treatment visit, no study medication 
was administered with the breakfast test meals while three tablets of study medication were administered with the lunch test meal.

Stable-isotope studies Stable-isotope methods were used to assess glucose, lipid (DNL and DNCS) and bile acid metabolism in the fasting state and during meal tolerance tests (Fig. 2) before and after 12 weeks of treatment. Stableisotope-labelled compounds from Isotec (Miamisburg, OH, USA) or Cambridge Isotopes (Somerville, MA, USA) were $>99 \%$ enriched. Body composition was assessed by bioelectrical impedance analysis (Tanita TBF-300A, Arlington Heights, IL, USA). On the evening of admission, participants received an ad libitum low-fat meal $(\leq 30 \%$ fat $)$ at $18: 00$ hours. At 22:00 hours a continuous $19.5 \mathrm{~h}$ infusion of $\left[1-{ }^{13} \mathrm{C}_{1}\right]$ acetate $(10 \mathrm{mg} / \mathrm{min})$ was started to assess fractional DNL, fractional DNCS and the fraction of cholic acid (CA) and chenodeoxycholic acid (CDCA) derived from newly synthesised cholesterol. At 00:30 hours of day 2 , a primed/continuous $6 \mathrm{~h}\left[2-{ }^{13} \mathrm{C}_{1}\right]$ glycerol infusion $(15 \mathrm{mg} / \mathrm{kg}$ fat-free mass $[\mathrm{FFM}]$ prime, $0.25 \mathrm{mg}[\mathrm{kg} \mathrm{FFM}]^{-1} \mathrm{~min}^{-1}$ ) was started to assess GNG in the fasting state. At 02.30 hours a primed/continuous infusion of $\left[\mathrm{U}^{13} \mathrm{C}_{6}\right]$ glucose $(1.2 \mathrm{mg} / \mathrm{kg}$ body weight prime, $0.02 \mathrm{mg}[\mathrm{kg} \text { body weight }]^{-1} \mathrm{~min}^{-1}$ ) was started to assess the rate of appearance $\left(R_{\mathrm{a}}\right)$ of glucose in the fasting state (this low tracer infusion rate was chosen to avoid isotopic interference by label derived from $\left[\mathrm{U}_{-}{ }^{13} \mathrm{C}_{6}\right]$ glucose with the GNG measurement from $\left[2-{ }^{13} \mathrm{C}_{1}\right]$ glycerol [14]). At 06:30 hours the $\left[\mathrm{U}_{-}{ }^{13} \mathrm{C}_{6}\right]$ glucose infusion rate was increased to $0.08 \mathrm{mg}$ [ $\mathrm{kg}$ body weight $]^{-1} \mathrm{~min}^{-1}$ to calculate total glucose $R_{\mathrm{a}}$ during a breakfast meal (the infusion rate was increased to maintain sufficient enrichments of blood $\left[\mathrm{U}_{-}{ }^{13} \mathrm{C}_{6}\right]$ glucose in the presence of dilution from the breakfast meal). At 08:30 hours a standardised breakfast meal $(2,531 \mathrm{~kJ}$ with $51 \%$ carbohydrate, $33 \%$ fat and $16 \%$ protein) was administered consisting of $70 \mathrm{~g}$ egg, $70 \mathrm{~g}$ mozzarella cheese and $75 \mathrm{~g}$ glucose, of which $15 \mathrm{~g}$ was $\left[6,6-{ }^{2} \mathrm{H}_{2}\right]$ glucose given as a flavoured aqueous solution to measure the kinetics of exogenous glucose appearance in blood (referred to as glucose absorption) [15] and to measure whole-body glycolytic disposal of the glucose load [16]. Participants consumed the egg and cheese within the first $5 \mathrm{~min}$ followed by the glucose drink in the next $5 \mathrm{~min}$. A standardised lunch meal $(3,539 \mathrm{~kJ}, 51 \%$ carbohydrate, $26 \%$ fat and $23 \%$ protein) was given at 13:30 hours and consumed within $30 \mathrm{~min}$.

Blood was drawn at 05:30, 06:00, 06:15, 06:30, and 08:30 hours of day 2 to assess fasting variables. Blood samples were also obtained 15, 30, 45, 60, 90, 120, 150, $180,210,240,270,300$ (lunch meal was administered immediately after $300 \mathrm{~min}$ blood sample), 360, 420, 480 and $540 \mathrm{~min}$ after the breakfast meal.
Assay methods Blood was collected in tubes containing EDTA (bile acids, lipids and insulin), sodium fluoride potassium oxalate (glucose and ${ }^{2} \mathrm{H}_{2} \mathrm{O}$ ) and dipeptidyl peptidase-4 inhibitor plus aprotinin (incretins and glucagon). Plasma was stored at $-80^{\circ} \mathrm{C}$. Glucose concentrations were determined with an YSI glucose analyser (YSI 2700). Lipid profiles were assayed using an automated chemistry immunoanalyser by a central laboratory (DGD, San Antonio, TX, USA). $\mathrm{HbA}_{1 \mathrm{c}}$ was determined by each site's local clinical laboratory. Plasma insulin (human specific), total GLP-1 and glucagon concentrations were analysed by radioimmunoassay (Millipore, St Charles, MO, USA). Total GIP, active GLP-1 (Millipore, St Charles, MO, USA) and fibroblast growth factor-19 (FGF-19) concentrations (R\&D Systems, Minneapolis, MN, USA) were determined by ELISA. Plasma NEFA concentrations were analysed with an enzymatic colorimetric method (Wako, Richmond, VA, USA). Plasma ${ }^{2} \mathrm{H}_{2} \mathrm{O}$ content was analysed as a measure of the glycolytic disposal of the oral $\left[6,6-{ }^{2} \mathrm{H}_{2}\right]$ glucose, as described by Beysen et al. [16]. This involved distillation of $50 \mu \mathrm{l}$ plasma in the cap of an inverted vial, in a $45^{\circ} \mathrm{C}$ glass bead-filled heating block placed for $3 \mathrm{~h}$ in refrigerator to ensure prevention of in vitro ${ }^{2} \mathrm{H}_{2} \mathrm{O}$ production from labelled glucose.

GC/MS analysis $\left[\mathrm{U}_{-}{ }^{13} \mathrm{C}_{6}\right]$ glucose and $\left[6,6-{ }^{2} \mathrm{H}_{2}\right]$ glucose enrichment was analysed from deproteinized plasma and converted to the aldonitrile penta-acetate derivative for GC/MS analysis [17]. VLDL were isolated from plasma by sequential ultracentrifugation; total lipids were extracted from VLDL particles with chloroform:methanol (2:1); and VLDL-triacylglycerols were then isolated via thin layer chromatography [18]. VLDL-triacylglycerol fatty acids were then trans-esterified to fatty acid-methyl esters for GC/MS [19]. Plasma total bile acids collected at 17:30 hours ( $4 \mathrm{~h}$ after the lunch test meal) were deconjugated with choloylglycine hydrolase $(1 \mathrm{U} / \mu \mathrm{l})$ and converted to the pentafluoro-benzyl ester trimethylsilyl ether derivative for GC/MS analysis [20]. Both the primary bile acids, CA and CDCA, were analysed. Cholesterol was extracted from plasma with $95 \%$ ethanol-acetone and non-esterified cholesterol was converted to its acetyl derivative for GC/MS analysis [21].

Calculations In the steady or fasting state, EGP was calculated as follows:

$$
\begin{aligned}
\mathrm{EGP}= & \frac{\left[\mathrm{U}-{ }^{13} \mathrm{C}_{6}\right] \text { glucose infusion rate }}{\left[\mathrm{U}-{ }^{13} \mathrm{C}_{6}\right] \text { glucose enrichment }} \\
& -\left[\mathrm{U}-{ }^{13} \mathrm{C}_{6}\right] \text { glucose infusion rate }
\end{aligned}
$$

The fraction of plasma glucose that was synthesised by GNG was calculated by mass isotopomer distribution 
analysis (MIDA) [22] and absolute GNG was calculated as EGP $\times$ fractional GNG. The absolute contribution to plasma glucose from glycogen (glycogenolysis) was calculated as EGP-absolute GNG. Fasting plasma glucose clearance was calculated as the rate of disappearance of glucose (identical to $R_{\mathrm{a}}$ glucose under steady-state conditions) divided by the fasting plasma glucose concentration [23]. HOMA-insulin resistance (HOMA-IR) and HOMA-beta cell function (HOMA-B) were calculated as previously described [24]. Glucose fluxes during the mixed breakfast meal were measured using a dual tracer method [25] and calculated using non-steady state equations of Steele et al. [25] and a total distribution volume of $160 \mathrm{ml} / \mathrm{kg}$. Fractional DNL, DNCS, CA and CDCA synthesis were calculated using MIDA [26, 27]. Fractional DNC represents the fraction of newly synthesised nonesterified cholesterol in plasma. Fractional $\mathrm{CA}$ and CDCA represent the relative amounts of CA and CDCA made from newly synthesised cholesterol. Fractional DNL represents the fraction of palmitate in VLDLtriacylglycerol that was newly synthesised during the period of the $\left[1-{ }^{13} \mathrm{C}_{1}\right]$ acetate infusion. Glycolytic disposal of oral glucose was measured $5 \mathrm{~h}$ after the administration of the breakfast meal and calculated as the total amount of ${ }^{2} \mathrm{H}_{2} \mathrm{O}$ released from $15 \mathrm{~g}$ of $\left[6,6-{ }^{2} \mathrm{H}_{2}\right]$ glucose administered with the breakfast test meal [16]. Total AUC values were calculated by the trapezoid method using all results measured between 0 and $300 \mathrm{~min}$ (fasting concentrations included).

Statistical analysis Baseline differences between the two groups were evaluated using independent groups $t$ tests. Treatment differences and within-group effects were evaluated using mixed-effects regression models. These models had fixed effects of treatment, visit and treatment by visit interaction and a random subject effect. Variables with markedly non-normal residual distributions were reanalysed using estimates from 2,000 bootstrap samples. Baseline values of fasting plasma GLP-1 were added to the model to correct for GLP-1 differences at baseline. Spearman correlations were used to look at associations between variables. Data are means $\pm \mathrm{SE}$, except for treatment differences which are expressed as least squares means \pm SE or unless stated otherwise. $p$ values $<0.05$ were considered statistically significant.

\section{Results}

Participant characteristics One participant withdrew because of increased fasting triacylglycerol $(>5.65 \mathrm{mmol} / \mathrm{l})$ in the colesevelam group and four withdrew voluntarily. Data from one individual was excluded because of non- compliance with the protocol (Fig. 2). The baseline characteristics were not different between groups, with the exception of fasting total GLP-1 which was higher in the placebo group (Table 1). Usage of glucose-lowering medications was similar between groups.

Fasting metabolic variables After 12 weeks of treatment, there was a reduction in $\mathrm{HbA}_{1 \mathrm{c}}$ and fasting plasma glucose concentrations with colesevelam and a nonsignificant increase in the placebo group resulting in treatment differences of $-0.6 \pm 0.2 \%(-7 \pm 2 \mathrm{mmol} / \mathrm{mol} ; p<$ $0.01)$ for $\mathrm{HbA}_{1 \mathrm{c}}$ (Fig. 3a) and $-1.28 \pm 0.61 \mathrm{mmol} / \mathrm{l}(p<0.05)$ for fasting glucose (Fig. 3b). Of interest, colesevelam increased fasting plasma total GLP-1 concentrations compared with placebo, resulting in a treatment difference of $10 \pm 4 \mathrm{pmol} / 1 \quad(p<0.05$, Fig. $3 \mathrm{c})$. The treatment difference remained significant after correcting for the baseline difference in fasting total GLP-1 levels by covariance analysis $(9.2 \pm 2.6 \mathrm{pmol} / 1, p<0.001)$. No treatment differences were seen for fasting insulin, GIP and glucagon concentrations or glucagon to insulin ratio (data not shown). Compared with placebo, colesevelam treatment improved beta cell function (HOMA-B treatment difference: $+18 \% \pm 4$, $p<0.01$, Fig. 3d) but not insulin sensitivity (HOMA-IR, Fig. 3e). Within the colesevelam group fasting LDLcholesterol decreased (Fig. 3f) and fasting triacylglycerol increased (Fig. 3g) but these changes were not significant when compared to changes in the placebo group. No treatment effects were seen for fasting total cholesterol, HDL-cholesterol, and NEFA concentrations (data not shown).

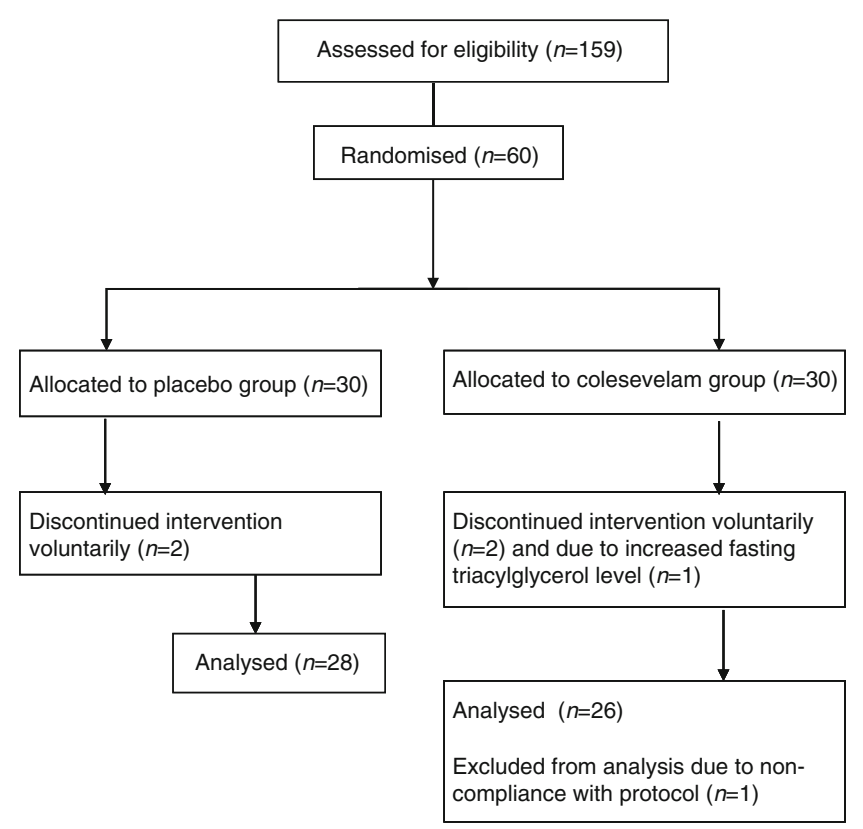

Fig. 1 Participant disposition chart 
Table 1 Baseline participant characteristics and fasting metabolic variables
Data are mean \pm SD (range) ${ }^{*} p<0.01$ vs colesevelam group SU, sulfonylurea

\begin{tabular}{|c|c|c|}
\hline Characteristic & Colesevelam & Placebo \\
\hline$n$ & 26 & 28 \\
\hline Sex (female/male) & $11 / 15$ & $13 / 15$ \\
\hline Age (years) & $59 \pm 9(40-69)$ & $56 \pm 9(33-70)$ \\
\hline Weight (kg) & $84 \pm 16(55-112)$ & $88 \pm 19(60-133)$ \\
\hline BMI $\left(\mathrm{kg} / \mathrm{m}^{2}\right)$ & $30 \pm 5(23-41)$ & $31 \pm 5(22-40)$ \\
\hline $\mathrm{HbA}_{1 \mathrm{c}}(\%)$ & $8.5 \pm 1.2(6.8-11.0)$ & $8.0 \pm 0.9(6.6-9.7)$ \\
\hline $\mathrm{HbA}_{1 \mathrm{c}}(\mathrm{mmol} / \mathrm{mol})$ & $69 \pm 2.6(51-97)$ & $64 \pm 1.8(49-83)$ \\
\hline Glucose (mmol/l) & $9.2 \pm 2.3(6.4-14.4)$ & $8.4 \pm 2.4(4.0-14.5)$ \\
\hline Insulin (pmol/1) & $76 \pm 42(28-215)$ & $97 \pm 42(35-208)$ \\
\hline HOMA-IR & $4.6 \pm 3.2(1.3-14.7)$ & $5.0 \pm 2.2(1.7-10.8)$ \\
\hline HOMA-B (\%) & $39 \pm 28(8-115)$ & $55 \pm 40(10-181)$ \\
\hline Total cholesterol (mmol/l) & $4.6 \pm 1.2(2.7-7.3)$ & $4.6 \pm 1.3(1.4-7.8)$ \\
\hline LDL-cholesterol (mmol/l) & $2.8 \pm 0.8(1.7-5.0)$ & $2.8 \pm 1.0(1.0-5.1)$ \\
\hline HDL-cholesterol (mmol/l) & $0.9 \pm 0.2(0.4-1.2)$ & $1.0 \pm 0.2(0.4-1.5)$ \\
\hline Triacylglycerol (mmol/l) & $2.2 \pm 0.8(1.0-4.2)$ & $2.0 \pm 0.9(0.5-3.9)$ \\
\hline NEFA $(\mu \mathrm{mol} / 1)$ & $441 \pm 127(181-680)$ & $468 \pm 87(292-619)$ \\
\hline Total GLP-1 (pmol/1) & $8.3 \pm 5.4(2-21)$ & $16.7 \pm 13.5(2-57)^{*}$ \\
\hline Active GLP-1 (pmol/l) & $3.2 \pm 1.8(2.0-8.1)$ & $3.4 \pm 2.3(2.0-10.3)$ \\
\hline Total GIP (pmol/l) & $9.9 \pm 4.3(4.2-19.9)$ & $10.6 \pm 7.2(4.9-43.4)$ \\
\hline Glucagon (pg/ml) & $82 \pm 34(23-196)$ & $92 \pm 37(52-193)$ \\
\hline \multicolumn{3}{|l|}{ Fasting glucose kinetics } \\
\hline Plasma glucose clearance $\left(\mathrm{ml}[\mathrm{kg} \mathrm{FFM}]^{-1} \mathrm{~min}^{-1}\right)$ & $2.8 \pm 0.6(2.5-2.9)$ & $3.0 \pm 0.9(2.1-5.7)$ \\
\hline EGP $\left(\mu \mathrm{mol}[\mathrm{kg} \mathrm{FFM}]^{-1} \min ^{-1}\right)$ & $24.1 \pm 4.9(17.0-35.8)$ & $22.4 \pm 4.4(16.0-34.6)$ \\
\hline Glycogenolysis $\left(\mu \mathrm{mol}[\mathrm{kg} \mathrm{FFM}]^{-1} \mathrm{~min}^{-1}\right)$ & $16.2 \pm 3.9(11.90-20.2)$ & $14.6 \pm 3.3(9.0-23.6)$ \\
\hline GNG $\left(\mu \mathrm{mol}[\mathrm{kg} \mathrm{FFM}]^{-1} \min ^{-1}\right)$ & $8.0 \pm 1.9(3.7-12.3)$ & $7.8 \pm 2.0(4.8-11.5)$ \\
\hline \multicolumn{3}{|l|}{ Concomitant oral anti-diabetic drug } \\
\hline SU alone & 4 & 2 \\
\hline Metformin alone & 16 & 20 \\
\hline SU plus metformin & 5 & 5 \\
\hline Diet alone & 1 & 1 \\
\hline
\end{tabular}

$(1.2 \mathrm{mg} / \mathrm{kg} \mathrm{BW})$

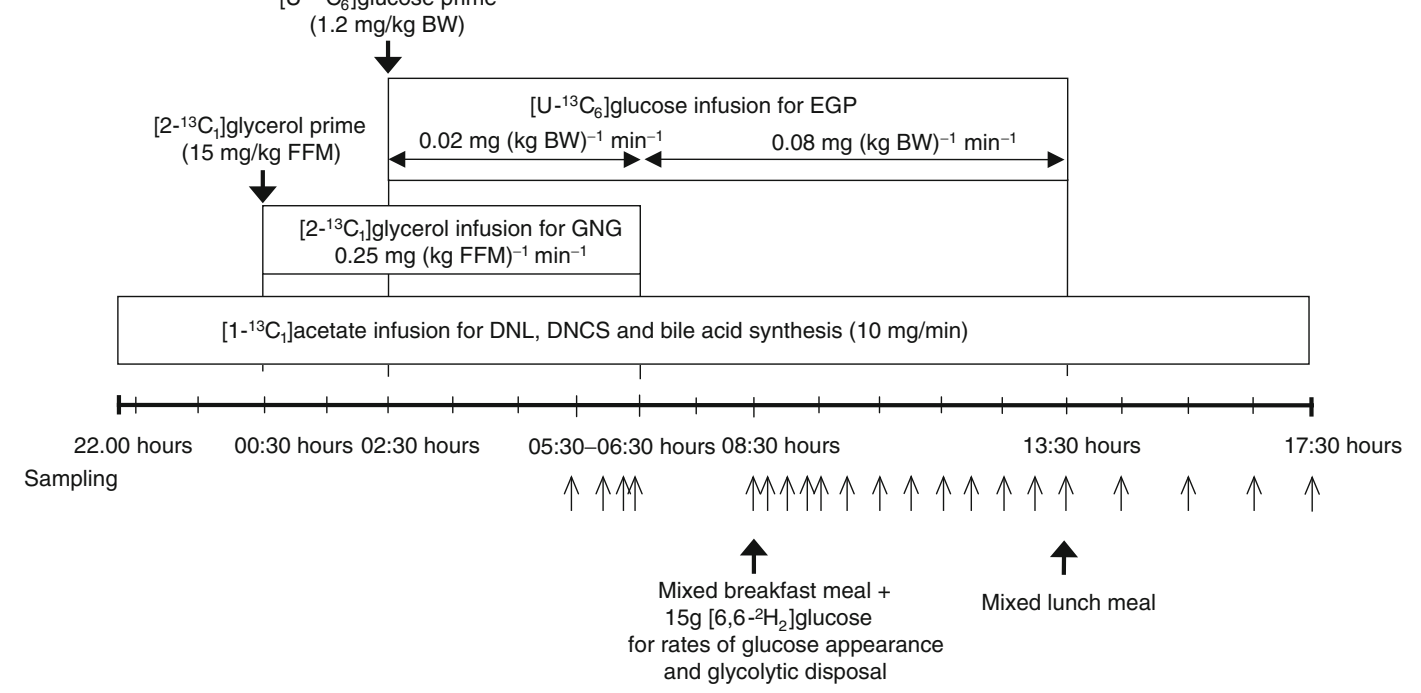

Fig. 2 Stable isotope infusion and meal protocol. BW, body weight. Thin upward arrows indicate a blood draw 


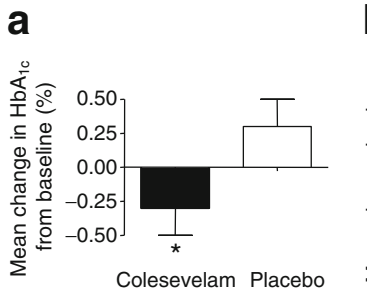

e

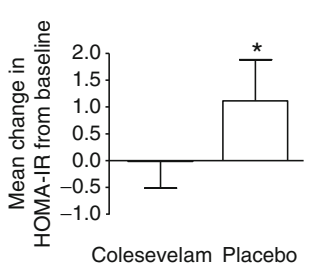

b

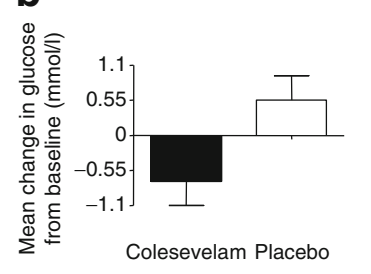

f
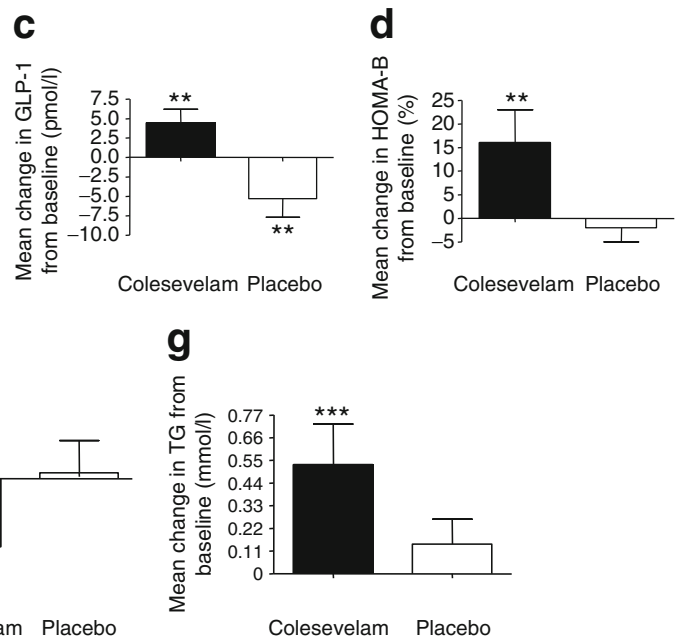

Fig. 3 Mean changes from baseline after 12 weeks of colesevelam or placebo: (a) $\mathrm{HbA}_{1 \mathrm{c}}(-0.6 \pm 0.2 ; p<0.01)$; (b) fasting plasma glucose $(-1.3 \pm 0.6 ; p<0.05)$; (c) fasting total GLP-1 (10.3 $\pm 4.2 ; p<0.05)$; (d) HOMA-B (18 \pm ; $p<0.01)$; (e) HOMA-IR (NS); (f) fasting

Postprandial metabolic variables The effects of treatment on postprandial glycaemic variables were evaluated during a standardised breakfast test meal (Table 2). Relative to placebo, colesevelam treatment reduced glucose AUC over $5 \mathrm{~h}$ although when glucose AUC was adjusted for fasting concentrations it did not differ between the groups. Colesevelam increased total GLP-1 and GIP AUCs and the active GLP-1 AUC showed a trend to increase. No treatment differences were found for postprandial insulin, glucagon or glucagon:insulin AUCs.
LDL-cholesterol $(-0.3 \pm 0.2 ; \mathrm{NS})$; and (g) fasting triacylglycerol $\left(-0.4 \pm 0.2\right.$; NS) Data are means \pm SE. ${ }^{*} p<0.05,{ }^{* *} p<0.01, * * * p<$ 0.001 for pre- vs post-treatment

Fasting and postprandial glucose kinetics Glucose kinetic variables measured at baseline did not differ between the two groups (Table 1). Colesevelam treatment significantly increased fasting plasma glucose clearance (Fig. 4a), but did not affect EGP, glycogenolysis or GNG in the fasting state (Fig. 4b-d) when compared with placebo. Despite the lack of a significant treatment effect, fasting EGP significantly increased in the untreated group (Fig. 4b) because of an increase in glycogenolysis (Fig. 4c); this increase was not seen in the colesevelam group. Following a test meal,
Table 2 Effect of treatment on postprandial glucose and hormone variables

Data are mean $\pm \mathrm{SE}$

Least squares means $\pm \mathrm{SE}$ were calculated for treatment differences

${ }^{*} p<0.05$ significantly different from colesevelam group; ${ }^{\dagger} p<0.05,{ }^{\dagger} p<0.01$ significantly different from baseline visit

\begin{tabular}{|c|c|c|c|c|}
\hline Variable & Baseline & Week 12 & Change & $\begin{array}{l}\text { Treatment difference } \\
\text { ( } p \text { value) }\end{array}$ \\
\hline \multicolumn{5}{|c|}{ Glucose AUC $(\mathrm{mmol} / 1 \times \mathrm{min})$} \\
\hline Colesevelam & $12.9 \pm 0.6$ & $12.0 \pm 0.6$ & $-0.8 \pm 0.4$ & \multirow[t]{2}{*}{$-1.3 \pm 0.7(<0.05)$} \\
\hline Placebo & $11.8 \pm 0.5$ & $12.4 \pm 0.6$ & $0.5 \pm 0.4$ & \\
\hline \multicolumn{5}{|c|}{ Insulin AUC $(\mathrm{pmol} / 1 \times \mathrm{min})$} \\
\hline Colesevelam & $333 \pm 35$ & $347 \pm 35$ & $14 \pm 14$ & \multirow[t]{2}{*}{$382 \pm 243(\mathrm{NS})$} \\
\hline Placebo & $479 \pm 69^{*}$ & $444 \pm 56$ & $-42 \pm 27$ & \\
\hline \multicolumn{5}{|c|}{ Total GLP-1 AUC $(\mathrm{pmol} / 1 \times \min )$} \\
\hline Colesevelam & $19 \pm 2$ & $23 \pm 2$ & $5 \pm 2^{\dagger}$ & \multirow[t]{2}{*}{$8 \pm 3(<0.01)$} \\
\hline Placebo & $25 \pm 3$ & $22 \pm 2$ & $-3 \pm 1$ & \\
\hline \multicolumn{5}{|c|}{ Active GLP-1 AUC $(\mathrm{pmol} / 1 \times \min )$} \\
\hline Colesevelam & $7.2 \pm 0.9$ & $7.9 \pm 1.1$ & $1.0 \pm .8$ & \multirow[t]{2}{*}{$0.9 \pm 0.8(\mathrm{NS})$} \\
\hline Placebo & $7.5 \pm 0.8$ & $7.0 \pm 0.6$ & $-0.6 \pm 0.5$ & \\
\hline \multicolumn{5}{|c|}{ Total GIP AUC $(\mathrm{pmol} / 1 \times \min )$} \\
\hline Colesevelam & $47 \pm 3$ & $53 \pm 4$ & $7 \pm 2^{\dagger \dagger}$ & \multirow[t]{2}{*}{$13 \pm 3(<0.001)$} \\
\hline Placebo & $46 \pm 3$ & $41 \pm 3$ & $-6 \pm 2^{\dagger \dagger}$ & \\
\hline \multicolumn{5}{|c|}{ Glucagon AUC $(\mathrm{pg} / \mathrm{ml} \times \min )$} \\
\hline Colesevelam & $89 \pm 6$ & $93 \pm 6$ & $4 \pm 3$ & \multirow[t]{2}{*}{$8 \pm 5$ (NS) } \\
\hline Placebo & $95 \pm 7$ & $91 \pm 6$ & $-4 \pm 4$ & \\
\hline
\end{tabular}


a

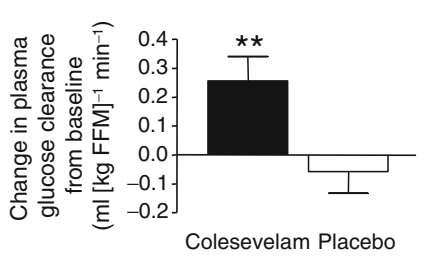

b

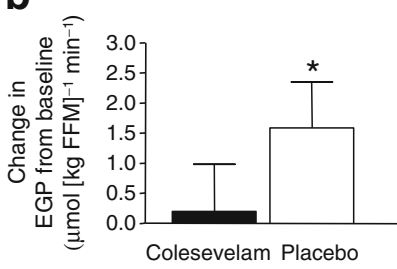

Fig. 4 Mean changes from baseline of fasting plasma glucose clearance ( $p<0.01$ between treatments) (a), fasting EGP (NS difference between treatments) (b), fasting glycogenolysis (NS difference between

colesevelam treatment had no effect on the appearance rate (absorption) of meal glucose, EGP, Ra total glucose or total glucose disposal rate $\left(R_{\mathrm{d}}\right.$; Fig. $\left.5 \mathrm{a}-\mathrm{h}\right)$ but did increase glycolytic disposal of the oral glucose load (Fig. 6), implying an effect on the partitioning of the meal between glycolysis and glycogen storage or on entry into tissues from the extravascular space, compared with placebo.

Fibroblast growth factor-19 (FGF-19) At baseline, fasting FGF-19 concentrations were $126 \pm 20 \mathrm{pg} / \mathrm{ml}$ for the placebo group and $175 \pm 24 \mathrm{pg} / \mathrm{ml}$ for the colesevelam group (no significant difference between groups) and $2 \mathrm{~h}$ after the administration of the lunch meal increased to $269 \pm 30 \mathrm{pg} / \mathrm{ml}$ in the placebo group ( $p<0.0001$ vs fasting) and to $419 \pm$ $63 \mathrm{pg} / \mathrm{ml}$ in the colesevelam group ( $p<0.0001$ vs fasting). Fasting and postprandial FGF-19 concentrations did not change after placebo treatment while colesevelam treatment reduced both, resulting in significant placebo-corrected reductions with colesevelam treatment for both fasting $(-119 \pm 33 \mathrm{pg} / \mathrm{ml}, p<0.001)$ and postprandial $(-251 \pm 67 \mathrm{pg} / \mathrm{ml}$, $p<0.001)$ FGF-19 concentrations.
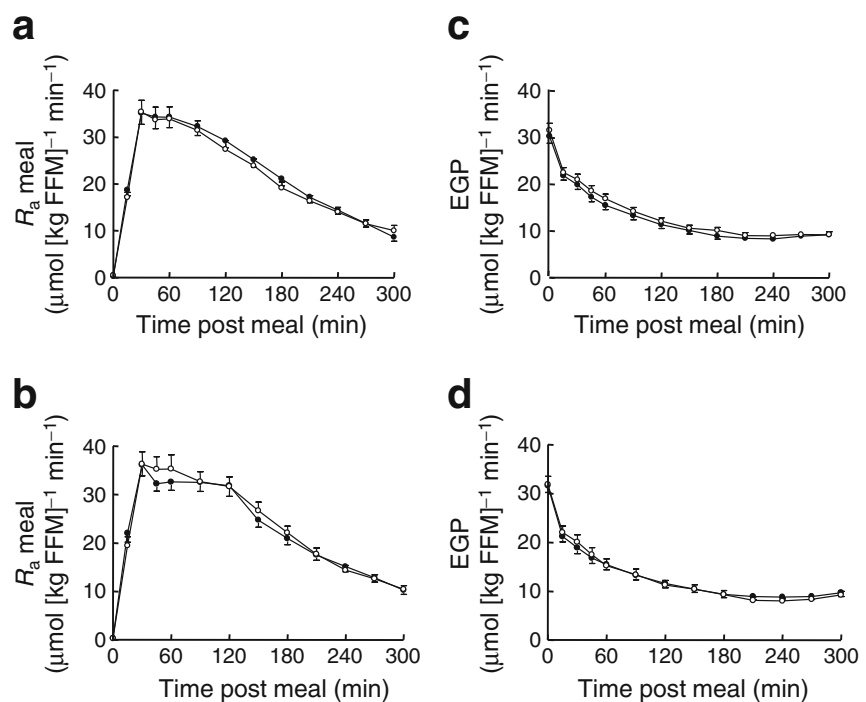

Fig. 5 Effect of treatment on the following variables measured during a breakfast test meal before and following 12 weeks of treatment: $R_{\mathrm{a}}$ for meal glucose with (a) placebo and (b) colesevelam; EGP with (c) placebo and (d) colesevelam; $R_{\mathrm{a}}$ for total glucose with (e) placebo and

C

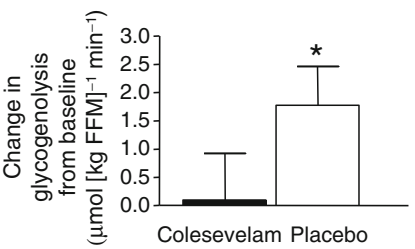

d

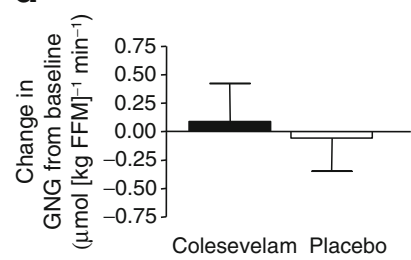

treatments) (c) and fasting GNG (NS difference between treatments) (d) after 12 weeks of placebo or colesevelam treatment. Data are means \pm SE. ${ }^{*} p<0.05,{ }^{* *} p<0.01$ for pre- vs post-treatment

De novo lipogenesis, cholesterol and bile acid kinetics Baseline fractional contribution of DNL to fasting VLDLtriacylglycerol was $6.2 \pm 0.4 \%$ for the placebo group and $6.4 \pm 0.5 \%$ for the colesevelam group (not significant). Fractional DNL increased steadily in the postprandial state after an approximately $2 \mathrm{~h}$ delay (Fig. 7a,b). This delay presumably represents the time required for newly synthesised fatty acids to be assembled into VLDL and released into the circulation. Fasting and postprandial fractional DNL increased in the placebo group (Fig. 7a) and did not change after colesevelam treatment (Fig. 7b), although the treatment effect did not reach statistical significance. Baseline DNCS was $4-6 \%$ in both groups (Fig. 7c,d). There was an approximately twofold increase in fractional DNCS with colesevelam (Fig. 7d) and no change with placebo treatment (Fig. 7c), resulting in a treatment difference of $3.7 \pm 0.2 \%(p<0.0001$, mean difference of all time points). At baseline, the contribution of newly synthesised cholesterol to CA $(2.5 \pm 0.7 \%$ for placebo and $2.5 \pm 0.6 \%$ for colesevelam $)$ and to CDCA $(2.5 \pm 0.5 \%$ for placebo and $1.6 \pm 0.3 \%$ for colesevelam) were not different
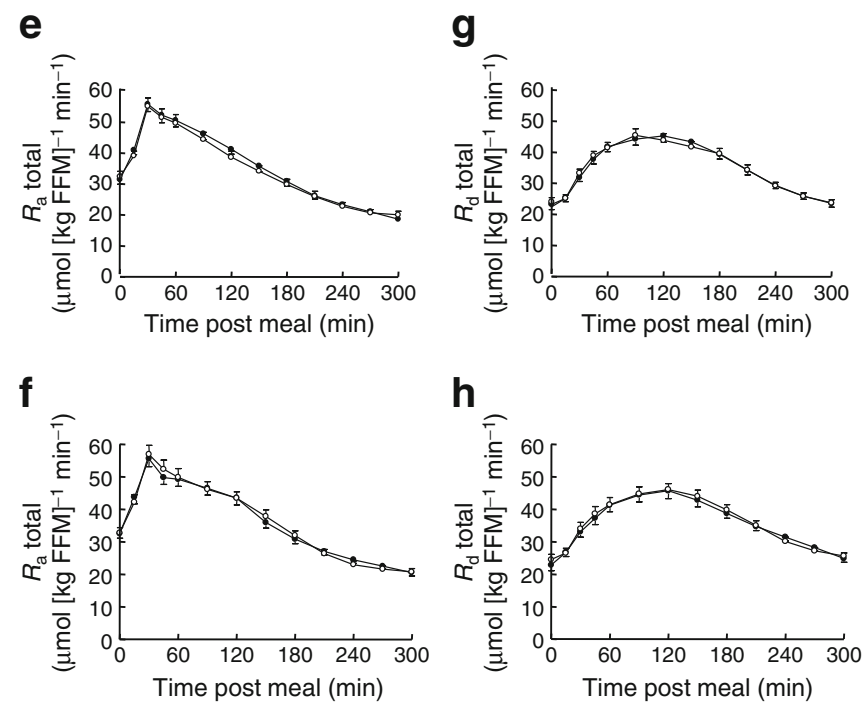

(f) colesevelam; and total glucose $R_{\mathrm{d}}$ with (g) placebo and (h) colesevelam. Data are means \pm SE. Black circles, pre-treatment; white circles, post-treatment 


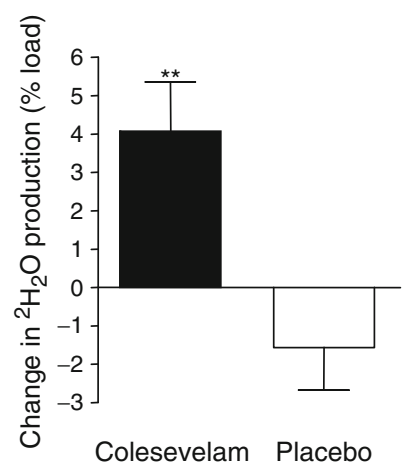

Fig. 6 Mean change from baseline of glycolytic disposal of an oral glucose load after placebo or colesevelam treatment $(p<0.01$ between treatments). The glucose load was administered as part of the breakfast test meal and glycolytic disposal was measured $5 \mathrm{~h}$ after the glucose load. Data are means \pm SE. ${ }^{* *} p<0.01$ pre- vs post-treatment

between groups. Colesevelam treatment increased the contribution of de novo synthesised cholesterol to both $\mathrm{CA}$ and CDCA while no change was seen with placebo treatment (Fig. 7e,f). The placebo-adjusted increase in CDCA synthesis from new cholesterol was significantly higher than the increase in CA synthesis from new cholesterol $(p<0.05)$ after colesevelam treatment.

Correlations At baseline, the fraction of bile acids synthesised from new cholesterol was significantly correlated with fasting FGF-19 $(r=-0.32, p<0.05$ for CDCA) and postprandial FGF-19 concentrations $(r=-0.31, p<0.05$ for CA and $r=-0.39, p<0.01$ for CDCA). Within the colesevelam group, changes in fasting plasma glucose clearance and glycolytic disposal of oral glucose were not correlated with changes in fractional DNCS, or the fractional contribution of DNCS to bile acids.

\section{Discussion}

This study was undertaken to explore the mechanisms of action for the glucose-lowering effect of colesevelam. As previously shown, this study confirmed that colesevelam lowers $\mathrm{HbA}_{1 \mathrm{c}}$ levels and fasting and postprandial glucose concentrations in participants with type 2 diabetes [28-30]. Using in vivo stable isotope-mass spectrometric techniques, we found that the improvement in glycaemic control with colesevelam was associated with an increase in plasma glucose clearance in the fasting state and by an increase in the glycolytic disposal of oral glucose in the postprandial state. Plasma glucose clearance reflects the ability of wholebody tissues to take up glucose in the fasting state, and could involve the liver or peripheral tissues. Plasma glucose clearance continued to be improved in the postprandial state ( $R_{\mathrm{d}}$ unchanged but at lower glucose concentrations with colesevelam) and this was reflected in the improvement seen in glycolytic disposal of oral glucose with colesevelam treatment. Glycolytic disposal of oral glucose occurs primarily in peripheral tissues and could reflect improved insulin sensitivity or insulin secretion. Previous investigations [11], using hyperinsulinaemic-euglycaemic glucose clamps, have shown that there is no effect of colesevelam on whole-body insulin sensitivity. Accordingly, the increase in the glycolytic disposal of oral glucose with colesevelam is most likely a result of improved beta cell function rather than a direct insulin-sensitising effect on peripheral tissues. Although plasma insulin concentrations did not change, we did find that colesevelam treatment resulted in a more robust beta cell response (as assessed by HOMA- $\beta$ ) for the degree of insulin resistance present, consistent with a role of improved beta cell function.

The improvement in glucose clearance and beta cell response with colesevelam might be the result of altered secretion of the incretin hormones GLP-1 and GIP, which a
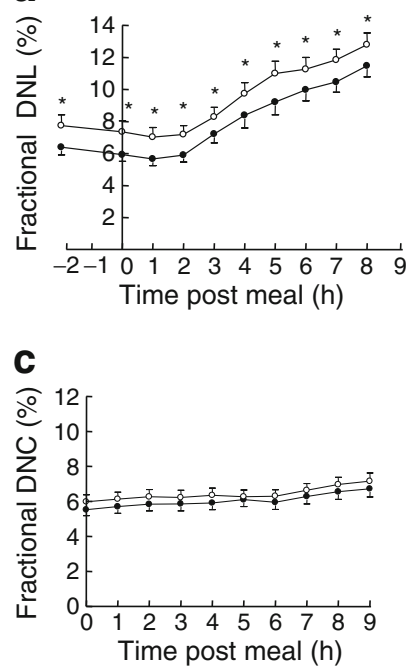

e

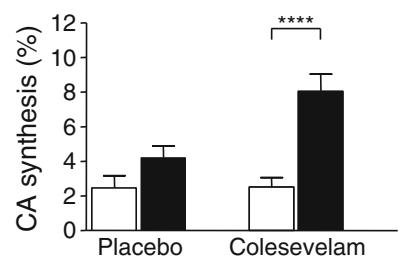

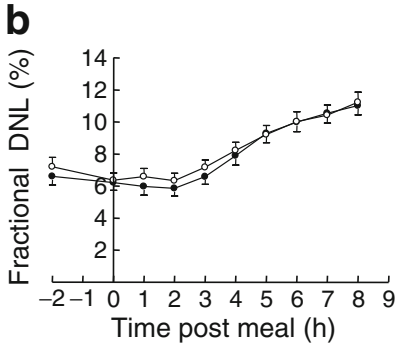

d
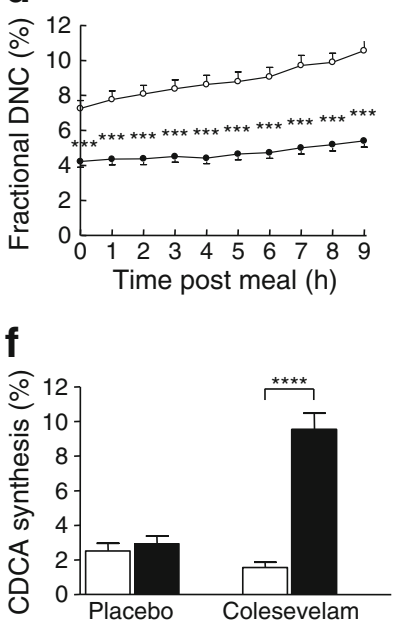

Fig. 7 Effects on fractional DNL (a,b) and fractional DNCS (c,d) of placebo $(\mathbf{a}, \mathbf{c})$ and colesevelam $(\mathbf{b}, \mathbf{d})$ before and after 12 weeks of treatment. The effect of treatment on the fractions of CA (e) and CDCA (f) that are synthesised from new cholesterol before (white bars) and after (black bars) 12 weeks of placebo or colesevelam treatment. A breakfast test meal was given at $0 \mathrm{~h}$ and a lunch test meal was given at $5 \mathrm{~h}$. The fractions of new CDCA and CA were measured at $9 \mathrm{~h}$ after the breakfast test meal (or 17:30 hours). Data are mean \pm SE. $* p<0.05, * * * p<0.001, * * * * p<0.0001$ pre- vs. post-treatment. In a-d: black circles, pre-treatment; white circles, post-treatment 
improve insulin secretion in the fasting [31, 33] and postprandial $[32,33]$ states. In support of this hypothesis, animal studies have shown an improvement in beta cell response [34, 35] and increased GLP-1 concentrations [34, 36] with treatment by BAS.

We show here for the first time in humans that colesevelam treatment increases plasma GLP-1 and GIP concentrations. An increase in GLP-1 concentrations ( $2 \mathrm{~h}$ postprandial) in humans had previously been reported with colestimide [37]. Bile acids activate the cell surface Gprotein-coupled receptor TGR5, which is expressed in enteroendocrine $\mathrm{L}$ cells and stimulates the secretion of GLP-1 [9]. It is not clear how BAS increase incretin secretion. It is possible that changes in the composition of the bile-acid pool or a change to a more hydrophilic bile acid pool with colesevelam [12] are involved in its incretinincreasing effect.

In addition to possible effects of colesevelam on peripheral tissues and beta cell response, colesevelam might also improve glucose control through an improvement in hepatic glucose metabolism. We observed a significant increase in fasting EGP in untreated participants through an increase in fasting glycogenolysis; this was not observed with colesevelam treatment. Weight did not change and participants were instructed to maintain their habitual diet and exercise regimens during the study, suggesting that the increase in EGP seen in the placebo group represents the natural disease progression. In addition, increased fasting glucose clearance with colesevelam treatment could reflect direct uptake of glucose by the liver for storage in glycogen (the direct pathway $[38,39]$ ), which in turn could account for the apparent stabilisation of hepatic glycogenolysis. The significance of this stabilising effect of colesevelam on EGP and glycogenolysis must be interpreted with caution because the treatment effect did not reach statistical significance. Nonetheless, evidence from the literature suggests that the increased GLP-1 levels reported with colesevelam treatment could mediate these effects. In type 2 diabetes, liraglutide, a long-acting GLP-1 derivative, decreased fasting EGP as a result of reduced glycogenolysis [40], and increasing GLP-1 concentrations by dipeptidyl peptidase-4 inhibition with vildagliptin increased hepatic glucose disposal [41]. In healthy people, the infusion of GLP-1 decreased fasting EGP and tended to increase plasma glucose clearance independent of changes in insulin and glucagon concentrations [42].

The lack of effect of colesevelam on GNG is interesting as activation of FXR has been shown to reduce expression of genes involved in gluconeogenesis in mice [43]. FXR has also been indicated to delay plasma appearance of orally administered glucose [44], but we did not find that colesevelam affects the $R_{\mathrm{a}}$ of oral glucose (absorption). We did not administer colesevelam with the test meal and cannot rule out that acute depletion of the bile acid pool with colesevelam may alter GNG and glucose absorption, however. In addition, although FGF-19 treatment has been shown to improve glucose control, the decrease in FGF-19 concentrations with BAS in this study did not result in increases in glucose concentrations.

These findings may indicate that changes in glucose metabolism with long-term colesevelam treatment are mediated through TGR5 activation and its subsequent increase in GLP-1 secretion rather than by effects on FXR activity. In support of this model, the glucose-lowering effects of colestyramine in Zucker diabetic fatty rats were not affected by the addition of an FXR agonist [34]. The effects of colesevelam on hepatic glucose metabolism without effects on GNG give it a different profile of metabolic actions than metformin [45] or other oral hypoglycaemic agents.

In addition to effects of colesevelam on glycaemic control, we also observed the well-known effects of BAS on bile acid and cholesterol synthesis [46]. Colesevelam treatment doubled the fractional contribution of endogenous synthesis to the non-esterified cholesterol pool. Colesevelam increased the fractional synthesis of CDCA and CA from newly synthesised cholesterol, although the main source for $\mathrm{CA}$ and CDCA remained pre-formed cholesterol. While it has been shown by others $[12,47]$ that increases in total BA synthesis for CA are greater than for CDCA, new cholesterol contributed more to the fractional synthesis of CDCA than to CA after colesevelam treatment. This may suggest that individual bile acids respond differently to BAS but also that the percentage contribution of newly synthesised cholesterol to CA vs CDCA may not depend on the total bile acid production rate. As shown previously [12], colesevelam treatment significantly reduced FGF-19 concentrations in both the fasting and the postprandial states. We also found that fasting and postprandial FGF-19 concentrations were negatively correlated with CDCA and CA synthesis in type 2 diabetes before treatment. Studies in healthy participants have suggested that BA synthesis is regulated in part by FGF-19 [12, 48], but a similar relationship in type 2 diabetes was not seen in a previous study [12].

FGF-19 has been shown to inhibit fatty acid synthesis in cultured hepatocytes [49] and bile acid sequestration in diabetic $d b / d b$ mice resulted in an increase in DNL [3]. We did not, however, see an increase in DNL with colesevelam treatment in patients with type 2 diabetes. Thus, the defect in leptin signalling in the $d b / d b$ mice may cause a metabolic shift toward fatty acid synthesis that colesevelam treatment exacerbates and that is unique to leptin deficiency. The lack of increase in DNL with colesevelam also suggests that any increase in plasma triacylglycerol seen with long-term 
colesevelam treatment in people with type 2 diabetes does not occur because of an increased contribution of newly synthesised fatty acids to circulating lipids.

In summary, the improvement in glucose control in type 2 diabetes with colesevelam was mediated through an increase in fasting plasma glucose clearance and an increase in glycolytic disposal of oral glucose. Colesevelam treatment also suppressed the rise in EGP and glycogenolysis seen in the placebo group in the fasting state. The improvement in glucose control with colesevelam was associated with increased GLP-1 and GIP concentrations. These effects suggest a predominant action of colesevelam on glucose homeostasis in the liver, distinct from the metabolic actions of metformin. Colesevelam also increased cholesterol synthesis and the proportion of bile acids derived from newly synthesised cholesterol, as expected, but unexpectedly had no effect on fractional DNL. The changes in glucose kinetics with colesevelam did not correlate with changes in bile acid and cholesterol kinetics, consistent with a previous report [12]. This suggests that effects on glucose control may be regulated independently from effects of colesevelam on lipid control.

Acknowledgements This work was funded by an investigatorinitiated grant from Daiichi Sankyo. We thank the Diabetes and Glandular Disease Research Center (San Antonio, TX, USA), Clinical Pharmacology of Miami (Miami, FL, USA), and Diablo Clinical Research (Walnut Creek, CA, USA) for conducting the clinical studies and the participants for taking part. We thank R. Neese (KineMed) for his assistance with the GNG measurements, A. Bostrom (consultant) for the statistical analysis and J. Edmonds (KineMed) for his assistance with glucose analysis.

Contribution statement $\mathrm{CB}$ was the primary investigator of the study, supervised the study, analysed and interpreted the data and wrote the manuscript. EM, ST and MH contributed to the design of the study, interpretation of the data and reviewed and edited the manuscript. AG contributed to data analysis and reviewed the manuscript. KD, ET, TR, JP and MC performed the sample analysis and contributed to interpretation of data and revisions to the manuscript. All authors approved the final version to be published.

Duality of interest C. Beysen, K. Deines, E. Tsang, A. Glass, S. Turner, J. Protasio and T. Riff are employees of KineMed and have KineMed stock options. M. Hellerstein is the co-founder and is Chief of SAB of KineMed. E. Murphy and M. Chan declare that there is no duality of interest associated with this manuscript.

\section{References}

1. Insull W Jr (2006) Clinical utility of bile acid sequestrants in the treatment of dyslipidemia: a scientific review. South Med J 99:257-273

2. Onishi T, Sano N, Takikawa H (2002) Effect of colestimide on absorption of unconjugated bile acids in the rat jejunum. $\mathrm{J}$ Gastroenterol Hepatol 17:697-701
3. Herrema H, Meissner M, van Dijk TH et al (2010) Bile salt sequestration induces hepatic de novo lipogenesis through farnesoid $\mathrm{X}$ receptor- and liver $\mathrm{X}$ receptor alpha-controlled metabolic pathways in mice. Hepatology 51:806-816

4. Goldfine AB (2008) Modulating LDL cholesterol and glucose in patients with type 2 diabetes mellitus: targeting the bile acid pathway. Curr Opin Cardiol 23:502-511

5. Lefebvre P, Cariou B, Lien F, Kuipers F, Staels B (2009) Role of bile acids and bile acid receptors in metabolic regulation. Physiol Rev 89:147-191

6. Ma K, Saha PK, Chan L, Moore DD (2006) Farnesoid X receptor is essential for normal glucose homeostasis. J Clin Invest 116:1102-1109

7. Zhang Y, Lee FY, Barrera G et al (2006) Activation of the nuclear receptor FXR improves hyperglycemia and hyperlipidemia in diabetic mice. Proc Natl Acad Sci U S A 103:1006-1011

8. Cariou B, van Harmelen K, Duran-Sandoval D et al (2006) The farnesoid $\mathrm{X}$ receptor modulates adiposity and peripheral insulin sensitivity in mice. J Biol Chem 281:11039-11049

9. Katsuma S, Hirasawa A, Tsujimoto G (2005) Bile acids promote glucagon-like peptide-1 secretion through TGR5 in a murine enteroendocrine cell line STC-1. Biochem Biophys Res Commun 329:386-390

10. Watanabe M, Houten SM, Mataki C et al (2006) Bile acids induce energy expenditure by promoting intracellular thyroid hormone activation. Nature 439:484-489

11. Schwartz SL, Lai YL, Xu J et al (2010) The effect of colesevelam hydrochloride on insulin sensitivity and secretion in patients with type 2 diabetes: a pilot study. Metab Syndr Relat Disord 8:179188

12. Brufau G, Stellaard F, Prado K et al (2010) Improved glycemic control with colesevelam treatment in patients with type 2 diabetes is not directly associated with changes in bile acid metabolism. Hepatology 52:1455-1464

13. Brufau G, Bahr MJ, Staels B et al (2010) Plasma bile acids are not associated with energy metabolism in humans. Nutr Metab 7:73

14. Hellerstein MK, Neese RA, Letscher A, Linfoot P, Turner S (1997) Hepatic glucose-6-phosphatase flux and glucose phosphorylation, cycling, irreversible disposal, and net balance in vivo in rats. Measurement using the secreted glucuronate technique. Metabolism: Clinical and Experimental 46:1390-1398

15. Gastaldelli A, Casolaro A, Pettiti M et al (2007) Effect of pioglitazone on the metabolic and hormonal response to a mixed meal in type II diabetes. Clin Pharmacol Ther 81:205-212

16. Beysen C, Murphy EJ, McLaughlin T et al (2007) Whole-body glycolysis measured by the deuterated-glucose disposal test correlates highly with insulin resistance in vivo. Diabetes Care 30:1143-1149

17. Van Dijk TH, Boer TS, Havinga R, Stellaard F, Kuipers F, Reijngoud DJ (2003) Quantification of hepatic carbohydrate metabolism in conscious mice using serial blood and urine spots. Anal Biochem 322:1-13

18. Beysen C, Murphy EJ, Nagaraja H et al (2008) A pilot study of the effects of pioglitazone and rosiglitazone on de novo lipogenesis in type 2 diabetes. J Lipid Res 49:2657-2663

19. Hellerstein MK, Christiansen M, Kaempfer S et al (1991) Measurement of de novo hepatic lipogenesis in humans using stable isotopes. J Clin Invest 87:1841-1852

20. Bisschop PH, Bandsma RH, Stellaard F et al (2004) Low-fat, highcarbohydrate and high-fat, low-carbohydrate diets decrease primary bile acid synthesis in humans. Am J Clin Nutr 79:570-576

21. Bandsma RH, Stellaard F, Vonk RJ et al (1998) Contribution of newly synthesized cholesterol to rat plasma and bile determined by mass isotopomer distribution analysis: bile-salt flux promotes secretion of newly synthesized cholesterol into bile. Biochem J 329:699-703 
22. Neese RA, Schwarz JM, Faix D et al (1995) Gluconeogenesis and intrahepatic triose phosphate flux in response to fasting or substrate loads. Application of the mass isotopomer distribution analysis technique with testing of assumptions and potential problems. J Biol Chem 270:14452-14466

23. Christiansen MP, Linfoot PA, Neese RA, Hellerstein MK (2000) Effect of dietary energy restriction on glucose production and substrate utilization in type 2 diabetes. Diabetes 49:1691-1699

24. Levy JC, Matthews DR, Hermans MP (1998) Correct homeostasis model assessment (HOMA) evaluation uses the computer program. Diabetes Care 21:2191-2192

25. Steele R, Bjerknes C, Rathgeb I, Altszuler N (1968) Glucose uptake and production during the oral glucose tolerance test. Diabetes 17:415-421

26. Neese RA, Faix D, Kletke C et al (1993) Measurement of endogenous synthesis of plasma cholesterol in rats and humans using MIDA. Am J Physiol 264:E136-E147

27. Hellerstein MK, Neese RA (1999) Mass isotopomer distribution analysis at eight years: theoretical, analytic, and experimental considerations. Am J Physiol 276:E1146-E1170

28. Fonseca VA, Rosenstock J, Wang AC, Truitt KE, Jones MR (2008) Colesevelam $\mathrm{HCl}$ improves glycemic control and reduces LDL cholesterol in patients with inadequately controlled type 2 diabetes on sulfonylurea-based therapy. Diabetes Care 31:14791484

29. Goldberg RB, Fonseca VA, Truitt KE, Jones MR (2008) Efficacy and safety of colesevelam in patients with type 2 diabetes mellitus and inadequate glycemic control receiving insulin-based therapy. Arch Intern Med 168:1531-1540

30. Zieve FJ, Kalin MF, Schwartz SL, Jones MR, Bailey WL (2007) Results of the glucose-lowering effect of WelChol study (GLOWS): a randomized, double-blind, placebo-controlled pilot study evaluating the effect of colesevelam hydrochloride on glycemic control in subjects with type 2 diabetes. Clin Ther 29:74-83

31. Ahren B, Larsson H, Holst JJ (1997) Effects of glucagon-like peptide-1 on islet function and insulin sensitivity in noninsulindependent diabetes mellitus. J Clin Endocrinol Metab 82:473-478

32. Zander M, Madsbad S, Madsen JL, Holst JJ (2002) Effect of 6-week course of glucagon-like peptide 1 on glycaemic control, insulin sensitivity, and beta-cell function in type 2 diabetes: a parallel-group study. Lancet 359:824-830

33. Vilsboll T, Krarup T, Madsbad S, Holst JJ (2003) Both GLP-1 and GIP are insulinotropic at basal and postprandial glucose levels and contribute nearly equally to the incretin effect of a meal in healthy subjects. Regul Pept 114:115-121

34. Chen L, McNulty J, Anderson D et al (2010) Cholestyramine reverses hyperglycemia and enhances glucose-stimulated glucagon-like peptide 1 release in Zucker diabetic fatty rats. J Pharmacol Exp Ther 334:164-170

35. Kogire M, Gomez G, Uchida T, Ishizuka J, Greeley GH Jr, Thompson JC (1992) Chronic effect of oral cholestyramine, a bile salt sequestrant, and exogenous cholecystokinin on insulin release in rats. Pancreas 7:15-20
36. Shang Q, Saumoy M, Holst JJ, Salen G, Xu G (2010) Colesevelam improves insulin resistance in a diet-induced obesity (F-DIO) rat model by increasing the release of GLP-1. Am J Physiol Gastrointest Liver Physiol 298:G419-G424

37. Suzuki T, Oba K, Igari Y et al (2007) Colestimide lowers plasma glucose levels and increases plasma glucagon-like PEPTIDE-1 (7-36) levels in patients with type 2 diabetes mellitus complicated by hypercholesterolemia. J Nippon Med Sch 74:338-343

38. Hellerstein MK, Greenblatt DJ, Munro HN (1986) Glycoconjugates as noninvasive probes of intrahepatic metabolism: pathways of glucose entry into compartmentalized hepatic UDP-glucose pools during glycogen accumulation. Proc Natl Acad Sci U S A 83:7044-7048

39. Katz J, McGarry JD (1984) The glucose paradox. Is glucose a substrate for liver metabolism? J Clin Invest 74:1901-1909

40. Degn KB, Juhl CB, Sturis J et al (2004) One week's treatment with the long-acting glucagon-like peptide 1 derivative liraglutide (NN2211) markedly improves 24-h glycemia and alpha- and betacell function and reduces endogenous glucose release in patients with type 2 diabetes. Diabetes 53:1187-1194

41. Edgerton DS, Johnson KM, Neal DW et al (2009) Inhibition of dipeptidyl peptidase-4 by vildagliptin during glucagon-like Peptide 1 infusion increases liver glucose uptake in the conscious dog. Diabetes 58:243-249

42. Prigeon RL, Quddusi S, Paty B, D'Alessio DA (2003) Suppression of glucose production by GLP-1 independent of islet hormones: a novel extrapancreatic effect. Am J Physiol Endocrinol Metab 285: E701-E707

43. Yamagata K, Daitoku H, Shimamoto Y et al (2004) Bile acids regulate gluconeogenic gene expression via small heterodimer partner-mediated repression of hepatocyte nuclear factor 4 and Foxo1. J Biol Chem 279:23158-23165

44. Van Dijk TH, Grefhorst A, Oosterveer MH et al (2009) An increased flux through the glucose 6-phosphate pool in enterocytes delays glucose absorption in $\mathrm{Fxr}^{-} /-$mice. J Biol Chem 284:10315-10323

45. Hundal RS, Krssak M, Dufour S et al (2000) Mechanism by which metformin reduces glucose production in type 2 diabetes. Diabetes 49:2063-2069

46. Einarsson K, Ericsson S, Ewerth S et al (1991) Bile acid sequestrants: mechanisms of action on bile acid and cholesterol metabolism. Eur J Clin Pharmacol 40(Suppl 1):S53-S58

47. Einarsson K, Hellstrom K, Kallner M (1974) The effect of cholestyramine on the elimination of cholesterol as bile acids in patients with hyperlipoproteinaemia type II and IV. Eur J Clin Invest 4:405-410

48. Lundasen T, Galman C, Angelin B, Rudling M (2006) Circulating intestinal fibroblast growth factor 19 has a pronounced diurnal variation and modulates hepatic bile acid synthesis in man. $\mathrm{J}$ Intern Med 260:530-536

49. Bhatnagar S, Damron HA, Hillgartner FB (2009) Fibroblast growth factor-19, a novel factor that inhibits hepatic fatty acid synthesis. J Biol Chem 284:10023-10033 